\title{
ISF special issue on emerging social and legal aspects of information systems with Web 2.0
}

\author{
Dickson K. W. Chiu • Eleanna Kafeza • \\ Patrick C. K. Hung
}

Published online: 5 May 2009

(C) Springer Science + Business Media, LLC 2009

The age of information and communication has revolutionized the way companies do business, especially in providing competitive and innovative services. Wireless technologies, peer-to-peer networks, grid computing, and agent technologies enable ubiquitous access to services and information systems with scalability (Chiu et al. 2009). This results in the removal of barriers of market expansion and new business opportunities as well as threats. In this new global and ubiquitous environment, it is of increasing importance to consider legal and social aspects in business services and information systems that will provide some level of certainty (Kafeza et al. 2005). In recent years, we have also witnessed a rapid proliferation of social computing Web sites and content. Social networking sites collect data about members and then store this information as user profiles. The data, or profiles, can then be shared among the members of the site. The goal of connecting people and social interactions is prompting the next wave of technol-

\footnotetext{
D. K. W. Chiu $(\bowtie)$

Dickson Computer Systems,

7A Victory Ave., 4th Floor, Homantin,

Kowloon, Hong Kong

e-mail: dicksonchiu@ieee.org

E. Kafeza

Department of Marketing and Communication,

Athens University of Economics and Business,

Patision 76,

10434 Athens, Greece

e-mail:kafeza@aueb.gr

P. C. K. Hung

Faculty of Business and Information Technology,

University of Ontario Institute of Technology (UOIT),

2000 Simcoe Street, North Oshawa,

Ontario L1H 7K4, Canada

e-mail: patrick.hung@uoit.ca
}

ogies supporting rapid development of these interpersonal interactions, which is called Web 2.0 (O'Reilly 2005). Web 2.0 is connecting more and more people, while amplifying their power of working together. Web 2.0 supports information sharing though communities and combines diverse sets of services from multiple sources which results in a novel personalized presentations of data.

Web 2.0 was formally proposed in a conference brainstorming session between O'Reilly and MediaLive International in 2004, though the concept had been around for a number of years before that. According to Tim O'Reilly's definition, Web 2.0 is the network platform spanning all connected devices. Successful Web 2.0 applications will be those that make the most advantages of that platform: delivering software as a continually updating service that benefits from more people using it, consuming and remixing data from multiple sources, while providing their own data and service in a form that allows remixing by others, creating network effects through an "architecture of participation," and going beyond the static page content of Web 1.0 to deliver rich user experiences. As a result of the emergence of Web 2.0, more nonprofessional programmers and end users are able to create simple applications through scripting languages and build composite documents.

Not only have new technologies like Asynchronous JavaScript and XML (AJAX), Rich Internet applications (RIA), and Mashup been introduced, but there is also a broad spectrum of vertical domains where legal and social issues influence the design and deployment of business services and information systems with Web 2.0. Examples include Web personalization and protection of user privacy in service provision, intellectual property rights protection when designing and implementing virtual works and multiplayer digital games, copyright protection in collabo- 
rative environments, automation of contracting and contract monitoring on the Web, protection of privacy in locationbased computing, etc.

This special issue of the ISF, Emerging Social and Legal Aspects of Information Systems with Web 2.0, contains extended versions of the best papers from the International Workshop on Social and Legal Aspects under Emerging Computing Environments (SLAECE 2008), in coordination with the Third International Conference on Internet and Web Applications and Services (ICIW 2008) at Athens, Greece on June 8-13, 2008 (Mellouk et al. 2008), as well as high quality papers from an open call for papers. This issue reflects the breadth of social and legal aspects of information systems topics. There are eight papers, each of which is concerned with a specific aspect of Web 2.0 social network computing and discussed in the following paragraphs.

Referring to the first paper "How Social Influence Affects We-Intention to Use Instant Messaging: The Moderating Effect of Usage Experience," Shen et al. (2009) present the use of instant messaging in team collaboration with changing roles of social influence behaviour in the formation of usage we-intention. Based on the belief-desire-intention model and the social influence theory, Shen et al. discuss an integrated model with an empirical study using survey data collected from 482 students.

Next, the second paper "Integrating constraints to support legally flexible business processes" by Sun et al. (2009) present a constraint-based business process management model, in which the security constraints restrict the dependencies between multiple activities. Sun et al. also show an illustrative prototype example for the model that is an application of property right exchange for supporting legal business processes.

Referring to the third paper "Integrating Organizational, Social, and Individual Perspectives in Web 2.0-Based Workplace E-Learning," Wang (2009) addresses the requirement of integrating organizational, social, and individual perspectives in the development of Web 2.0 e-learning systems. Wang also presents a key performance indicator (KPI)-oriented approach with Web 2.0 technologies

Then, Sasaki (2009) presents the fourth paper "A Computing Theory for Collaborative and Transparent Decision Making under Time Constraint" that describes a computing theory on the accelerated critical point of selected strategies between collaboration and competition for collaborative and transparent decision making under time constraint. This paper also discusses the proposed computing theory based on mathematical formulation with a feasibility test in a use case.

Further, Burgess et al. (2009) present the fifth paper "Trust perceptions of online travel information by different content creators: Some social and legal implications." Burgess et al. describe a study of the level of trustworthi- ness of online travel information. The study is based on a survey of Australian travel consumers and the results show that there are differences in the level of trust for online travel information from different sources.

Referring to the sixth paper "Towards Promoting Interactivity in a B2B Web Community," Adiele (2009) presents an interactivity model that dynamically measures the contributions of members of business-to-business Web communities. The model also determines the community's interactivity level with simulation studies to evaluate the performance of the model under various conditions.

Then, the seventh paper "A University-Oriented Web 2.0 Services Portal" by Zhang et al. (2009) discuss several key challenges and solutions in Web 2.0 mashup technology to build a university-oriented services portal. Zhang et al. present a two-layer mashup service model to support multiple granularities of services mashup and explore a caching technique to facilitate personalizable services requests.

Finally, in the eighth paper "A Study of the Impacts of Positive/Negative Feedback on Collective Wisdom - Case Study on Social Bookmarking Sites," Hwang et al. (2009) investigate how the positive/negative feedbacks would impact the quality of the collective wisdom within the social bookmarking sites.

In summary, the papers in this special issue illustrate some of the current research areas pertinent to emerging social and legal aspects of information systems with Web 2.0; while, in many ways, also amplifying the many challenges, which remain to be addressed. It is expected that new topics will emerge while existing research will shift concentration into this information systems frontier in the coming years.

\section{References}

Adiele, C. (2009). Towards promoting interactivity in a B2B Web community. Information Systems Frontier (in press).

Burgess, S., Sellitto, C., Cox, C., \& Buultjens, J. (2009). Trust perceptions of online travel information by different content creators: Some social and legal implications. Information Systems Frontier (in press).

Chiu, D. K. W., Yueh, Y. T. F., Leung, H.-F., \& Hung, P. C. K. (2009). Towards ubiquitous tourist service coordination and process integration: A collaborative travel agent system with semantic Web services. Information Systems Frontier, doi:10.1007/ s10796-008-9087-2.

Hwang, Y-C., Yuan, S-T., \& Weng, J-H. (2009). A study of the impacts of positive/negative feedback on collective wisdom case study on social bookmarking sites. Information Systems Frontier (in press).

Kafeza, I., Kafeza, E., \& Chiu D. K. W. (2005). Legal issues in agents for electronic contracting. Proceedings of the 38th Annual Hawaii International Conference on System Sciences (HICSS'05) - Track 5 (pp.134a, 10 pages), IEEE Computer Society Press. 
Mellouk, M., Bi, J., Ortiz, G., Chiu, D. K. W., \& Popescu, M. (Eds.) (2008). Proceedings of the 3rd International Conference on Internet and Web Applications and Services (ICIW 2008), 8-13 June 2008, Athens, Greece. IEEE Computer Society 2008. ISBN 978-0-7695-3163-2.

O'Reilly T. (2005). What is Web 2.0. O'Reilly network. http://www. oreillynet.com/pub/a/oreilly/tim/news/2005/09/30/what-is-web20.html. Retrieved 2009-03-16.

Sasaki, H. (2009). A computing theory for collaborative and transparent decision making under time constraint. Information Systems Frontier (in press).

Shen, A. X. L., Cheung, C. M. K., Lee, M. K. O., \& Chen, H. (2009). How social influence affects we-intention to use instant messaging: The moderating effect of usage experience. Information Systems Frontier (in press).

Sun, Y., Huang, J. Z. X., \& Meng, X. (2009). Integrating constraints to support legally flexible business processes. Information Systems Frontier (in press).

Wang, M. (2009). Integrating organizational, social, and individual perspectives in Web 2.0-based workplace e-learning. Information Systems Frontier (in press).

Zhang, J., Akula, K., Karim, M., \& Ariga, R. K. R. (2009). A university-oriented Web 2.0 services portal. Information Systems Frontier (in press).

Dickson K.W. Chiu received the B.Sc. (Hons.) degree in Computer Studies from the University of Hong Kong in 1987. He received the M.Sc. (1994) and the Ph.D. (2000) degrees in Computer Science from the Hong Kong University of Science and Technology, where he worked as a Visiting Assistant Lecturer after graduation. He also started his own computer company while studying part-time. From 2001 to 2003, he was an Assistant Professor at the Department of Computer Science and Engineering, the Chinese University of Hong Kong. He was a Visiting Assistant Professor in 2006 at the Computing Department, Hong Kong Polytechnic University for teaching M.Sc. courses. His research results have been published in over 100 papers in international journals and conference proceedings, including practical results of many master and undergraduate projects. $\mathrm{He}$ received a best paper award in the 37th Hawaii International Conference on System Sciences (HICSS) in 2004. He is the founding Editor-in-chief of the International Journal on Systems and ServiceOriented Engineering; Associate Editor of the International Journal of Organizational and Collective Intelligence, Knowledge Management \& E-Learning: An International Journal (KM\&EL), and Engineering Letters; and editorial board members of several international journals.
He co-founded several international workshops and co-edited several special issues in journals. He also served as a mini-track co-chair in the Decision Technologies track of HICSS, a theme (Service Intelligence and Service Science) co-chair in the International Conference of Machine Learning and Cybernetics, and program committee member in many international conferences. Dr. Chiu is a Senior Member of the ACM, a Senior Member of the IEEE, and a life member of the Hong Kong Computer Society.

Eleanna Kafeza is a lecturer at Athens University of Economics and Business. She received the $\mathrm{PhD}$ from Hong Kong University of Science and Technology, where she also held a visiting assistant lecturer position. Her research interests are in workflow management systems, legal issues in web contracting, web services and grid computing. She co-founded several international workshops, co-edited several special issues in journals, and has served in the program committee of many international conferences. She is an Associate Editor of International Journal on Systems and Service-Oriented Engineering as well as the International Journal of Organizational and Collective Intelligence.

Patrick C.K. Hung is an Associate Professor and IT Director at the Faculty of Business and Information Technology in UOIT and an Adjunct Faculty Member at the Department of Electrical and Computer Engineering in University of Waterloo. Patrick is currently collaborating with Boeing Phantom Works (Seattle, USA) and Bell Canada on security- and privacy-related research projects. He has filed two US patent applications on "Mobile Network Dynamic Workflow Exception Handling System." Patrick is also cooperating on Web services composition research projects with Southeast University in China. Recently he is working on a mobile healthcare project with the Hong Kong Red Cross with the Chinese University of Hong Kong. He is an executive committee member of the IEEE Computer Society's Technical Steering Committee for Services Computing, a steering member of EDOC "Enterprise Computing," and an associate editor/editorial board member/guest editor in several international journals such as the IEEE Transactions on Services Computing (TSC), International Journal of Web Services Research (JWSR) and International journal of Business Process and Integration Management (IJBPIM). He has been published more than 100 research and technical articles in International journals, conferences and workshops. 